\title{
TEXTOS SOBRE ESCRITURA CREATIVA. EL ORIGEN DE UNA DISCIPLINA
}

\author{
María del Pilar FRAILE AMADOR \\ Universidad Complutense de Madrid \\ pilar.fraile.amador@gmail.com
}

$\mathrm{P}$ retendemos en este trabajo plantear cuál es el origen de los textos contemporáneos que versan sobre la escritura creativa ${ }^{1}$ y cómo estos se constituyen en una disciplina nueva, que dista tanto de la poética clásica como de la crítica literaria. Revisaremos las dificultades de este proceso de formación y los caminos que se abren para la materia a partir de sus primeros textos.

Es cierto que desde la Poética de Aristóteles en el s. IV a. de C. hasta el siglo XIX hubo estudios sobre lo que podemos llamar «leyes o normas de la escritura literaria» tales como el Ars Poética de Horacio en el siglo I a. de C. o, por poner un ejemplo de la tradición castellana, La poética o reglas de la poesía en general y de sus principales especies, de Luzán en el siglo XVIII.

La mayor parte de estos textos siguen la tradición abierta por Aristóteles, esto es, suponen que las obras literarias tienen una estructura prefijada, así como unos temas, personajes, objetivos, etc., concretos y también suelen abundar en la idea de la obra literaria como mímesis de la naturaleza. Con estos presupuestos era harto difícil, como abajo veremos, acometer un estudio del proceso de escritura creativa que fuera más allá de la consideración de las formas supuestamente adecuadas para cada tipo de objeto que se pretenda imitar. No será hasta que estos presupuestos sobre la obra literaria queden desbancados cuando surgirá la necesidad y el anhelo de estudios específicos sobre el proceso de escritura literaria.

Así por ejemplo la Poética de Aristóteles, como es bien sabido, el estagirita se proponía «hablar no sólo de la poética misma sino también de sus especies y sus respectivas características, de la trama

\footnotetext{
${ }^{1}$ Entendemos aquí por «escritura creativa» la escritura de ficción en su más amplio sentido, que engloba todas las ramas de la literatura: desde la poesía al teatro pasando por la narrativa y el ensayo literario. Nótese que en el mundo anglosajón la palabra «ficción» tiene un uso más restringido que en castellano, pues habitualmente se usa para hablar de obras narrativas de todo tipo frente a lo que los anglosajones denominan «no ficción». La «no ficción» viene a corresponder con lo que en nuestra lengua puede ser el ensayo en un amplio sentido (que incluiría géneros como la biografía, los estudios humanísticos, la crónica, etc.). Además de eso en terminología anglosajona la escritura poética cae fuera de la categoría de «ficción», y se constituye como categoría propia.

Esta distinción terminológica tiene relevancia para este trabajo por cuanto que en muchos de los títulos que aquí se manejan son anglosajones y llevan en su título el término «ficción», usado en el restringido sentido que acabamos de explicar.
} 
requerida para componer un bello poema, del número y la naturaleza de las partes constitutivas de un poema y también de los restantes aspectos que atañen a la misma investigación» (Aristóteles, 1999: 3).

Los estudios de Horacio siguen en la estela de los de Aristóteles, considerando que hay un tipo de verso, por ejemplo, para cada tipo de sentimiento o expresión, y también asumen la idea del arte como imitación:

\author{
Hicieron el enojo y la impaciencia \\ Que Archíloco inventase versos Jambos \\ El sublime coturno en la Tragedia \\ Y el zueco en la comedia \\ Esta clase de verso usaron ambos, \\ Que imita bien el familiar discurso; \\ Que, aplacando el bullicio del concurso \\ Llama las atenciones; \\ Y cuadra á las dramáticas acciones (Horacio, 1777: 14).
}

Y otro tanto puede decirse de los de Luzán, así explica el autor la naturaleza de la poesía: «Hemos dicho ser la poesía imitación de la naturaleza, en lo universal y en lo particular; ahora es bien que expliquemos con toda claridad esta parte de nuestra definición, mayormente que de ella depende el entender bien todo el asunto» (Luzán, 1737: Libro I, Capítulo V, vII). Y respecto, por ejemplo a la composición de la poesía sostiene opiniones como la siguiente:

En tres diversos modos, según Aristóteles, puede imitar el poeta: simplemente narrando, o transformándose a veces en otra persona y narrando por boca ajena, o, finalmente, escondiendo enteramente su persona e introduciendo siempre otras que hablen. Cuanto al primer modo, pretenden algunos que la simple narración, no es imitación y que si lo fuese, también el historiógrafo, el orador, el físico y otros muchos que narran serían poetas. Pero como el término imitación, según dijimos en la definición de la poesía, es análogo, no hay duda que también la simple narración poética es imitación en este sentido. Y aunque es verdad que la historia y la oratoria imitan también con la simple narración, pero no en verso ni con invención y locución poética como la poesía (Luzán, 1737: Libro I, Capítulo X).

Podría suponerse que la poética, en su evolución como disciplina, acabó acogiendo los estudios sobre los métodos y procedimientos de escritura literaria de corte más moderno, como quizá hubiera sido natural. Sin embargo, la evolución de la disciplina no discurrió por esos derroteros sino que más bien se alejó de ellos.

A partir del formalismo ruso la poética tuvo un renacimiento. Jakobson, uno de los primeros críticos en hacerse eco de la poética como disciplina separada, la definía del siguiente modo: «Poética puede definirse como aquella parte de la lingüística que trata de la función poética y la relación con las demás funciones del lenguaje» (Jakobson, 1988: 42).

Esta definición excluye el tipo de aproximación que estamos estudiando, de hecho se aleja de la descripción del proceso creativo más aún que la tradición aristotélica.

Otros autores tampoco consideran que el objeto de la poética ni de la crítica literaria sean la descripción de los métodos y procedimientos de la escritura literaria.

Desde la semiótica de Todorov, por ejemplo, vemos la siguiente definición de poética:

El término poética, tal y como nos ha sido transmitido por la tradición designa: 1) toda teoría de la literatura; 2) la elección hecha por un autor entre todas las posibilidades (en el orden, la temática, de la 
composición, del estilo, etc.) literarias: "la poética de Hugo"; 3) los códigos normativos construidos por una escuela literaria, conjunto de reglas prácticas cuyo empleo se hace obligatorio (Todorov y Ducrot, 1975: 98).

Y en el mismo texto: «Ante todo, la poética debe responder a esta pregunta: ¿qué es la literatura? En otros términos, la poética procurará hacer de ese fenómeno sociológico que ha sido llamado "literatura" una entidad interna y teórica» (Todorov y Ducrot, 1975: 98).

Cierto es que desde la semiótica y el formalismo ruso las posiciones se han ido suavizando y ya no se exige a los estudios poéticos tanta especificidad. Sin embargo, tampoco las nuevas ideas acerca de la disciplina poética y menos de la crítica, consideran que el estudio del proceso de escritura forme parte de los cometidos de estas disciplinas.

Así por ejemplo Lubomír Dolezel en su Historia Breve de la poética dice:

El interés por los temas de este libro parte de la convicción - heredada de mi formación intelectualde que el compromiso con la literatura en la cultura occidental, desde sus orígenes en la Grecia antigua, siguió dos tradiciones distintas, paralelas, que a menudo se confunden: una, llamada crítica (criticism), la otra, poética (poetics). La crítica (término demasiado general en inglés), usado aquí con el sentido de «crítica literaria», es una actividad axiológica, valorativa, que integra o reintegra las obras literarias en el sistema de una cultura. La poética es una actividad cognitiva que agrupa el conocimiento más amplio adquirido por las ciencias humanas y sociales. Para la crítica, la obra literaria es un objeto de evaluación; para la poética, un objeto de conocimiento (Dolezel, 1977: 15).

Otros críticos como David Viñas Piquer, prefieren seguir englobando bajo el nombre de Crítica Literaria ambas actividades, según puede leerse en su Historia de la Crítica Literaria:

A este mismo sentido genérico de Crítica Literaria apela T. S. Eliot desde las páginas de Función de la poesía y función de la crítica: "Por crítica entiendo aquí toda la actividad intelectual encaminada, bien a averiguar qué es la poesía, cuál es su función, por qué se escribe, se lee o se recita, bien — suponiendo, más o menos conscientemente, que eso ya lo sabemos - a apreciar la verdadera poesía" (Viñas Piquer; 2007: 22).

Sigamos las categorías de unos u otro críticos, lo cierto es que en ninguno de los casos la crítica o la poética versarían, como decíamos, sobre cómo se escribe la obra de literaria: qué materiales, procedimientos, etc., son necesarios a este cometido.

El primer autor que reclamara la necesidad de una disciplina o un arte tal fue Novalis en los albores del siglo XIX, concretamente en 1798: «El arte de escribir no ha sido aún descubierto, pero está a punto de serlo, con bastantes semillas infecundas - pero esto que puede importar si alguna germina» (cit. en Rodari, 1983: 170). No es casualidad, como veremos abajo que sea precisamente un autor romántico el que empiece a vislumbrar que era posible la escritura de un arte de la escritura creativa.

Pero no fue hasta mediados del siglo XIX, cuando un autor se lanzará no sólo a reclamar la necesidad de la disciplina sino también a ensayar un primer texto sobre la materia, ese autor no fue otro que Edgar Allan, en su la Filosofía de la composición, publicada en 1846. Así se expresaba Poe respecto de la necesidad de estudios sobre la materia:

Frecuentemente he pensado en lo interesante que sería escribir un artículo por un autor que quisiera, es decir que pudiera contar, la marcha progresiva que ha seguido cualquiera de sus composiciones hasta llegar al término definitivo de su realización. Por qué tal trabajo no ha sido nunca presentado al público no es fácil de explicar; pero tal vez esa laguna literaria dependa en primer término de la vanidad de los autores (Poe, 2006: 204). 
Desde luego no fue solo Poe quien reclamó la necesidad de materiales acerca del oficio de la escritura sino que otros muchos autores se harán eco del mismo anhelo a partir de finales del siglo XIX.

Los primeros textos de esta resbaladiza disciplina tienden a incluir en sus títulos la palabra «Arte», distinguiéndose así de los acercamientos más crítico-teóricos o puramente normativos. No en vano también, y este es otro de los puntos fundamentales que diferencia este nuevo estudio, son textos escritos por escritores que describen, o tratan de describir su oficio.

Entre estos primeros textos incluimos:

La filosofía de la composición de Edgar Allan Poe de 1846, Consejos a jóvenes escritores de Charles Baudelaire, también publicado en 1846, El arte de la ficción de Henry James de 1884 así como Ensayos sobre el arte de escribir de Robert Louis Stevenson, publicado entre 1881 y 1899 y la Correspondencia ${ }^{2}$ de Flaubert publicada en su totalidad entre 1887 y 1893 . También pertenecerían a este corpus de textos clásicos, ya que fueron también escritos a finales del siglo XIX, aunque por diversas circunstancias no fueran publicados por primera vez hasta 1974 las cartas con consejos a escritores de Chéjov ${ }^{3}$.

También en España aparecen algunos ensayos breves, anotaciones y cartas de nuestros novelistas de finales de siglo diecinueve. Entre los mismos, podríamos citar: de Clarín, «La prensa y los cuentos», de Pardo Bazán, La Quimera o de Valera, J., Apuntes sobre el nuevo arte de escribir novelas. El desarrollo de la materia en España, no obstante, a no alcanza hasta bien entrado el siglo XX el desarrollo de la materia en otras latitudes ${ }^{4}$.

\footnotetext{
${ }^{2}$ Sus cartas no entran en el debate público hasta finales del siglo porque, a pesar de haber sido escritas durante la segunda mitad del siglo XIX — las que nos interesan se fechan entre 1845 y 1878 - , no empiezan a ser editadas hasta el año 1884. Concretamente en 1884, aparece la correspondencia entre Flaubert y George Sand, con un estudio introductorio de Guy de Maupassant: Lettres de Gustave Flaubert à George Sand, (precedidas por un estudio de Guy de Maupassant), Paris, G. Charpentier, 1884.

Y entre los años 1887 y 1893 se edita la correspondencia completa de Flaubert: Correspondance, Paris, G. Charpentier para las cuatro primeras series - y G. Charpentier et E. Fasquelle — para la cuarta serie —, 4 vol. $1^{\mathrm{a}}$ serie (1830-1850), precedidas de: «Souvenirs intimes» de Caroline Commanville, 1887. $2^{\mathrm{a}}$ serie (1850-1854), 1889. $3^{\mathrm{a}}$ serie $(1854-1869)$, 1891. $4^{\mathrm{a}}$ serie (1869-1880), 1893.

${ }^{3}$ Las cartas de Chéjov sobre el oficio de la escritura, recopiladas en España bajo el título: Consejos a un escritor, la versión que se ha usado para este trabajo, son extractadas directamente de las obras completas de Chéjov: Polnonie Sobranie Shochinenij í písem, Nauka, Moscú, 1974.

${ }^{4}$ Sería imposible en el espacio de este estudio explicar las obras que en la tradición española se dedican a la materia y por qué esta sufre tanto retraso con respecto de otras tradiciones europeas y de la tradición anglosajona. Sí diremos, sin embargo, que en la época que nos ocupa, la de la génesis de estos nuevos textos, las preocupaciones de los autores españoles fueron de carácter más teórico y si quisieron dedicarse al estudio de la práctica de la escritura, lo cierto es que no lo consiguieron en la mayoría de los casos. Así aunque el título del estudio de Valera, Apuntes sobre el nuevo arte de escribir novelas, nos podría hacer creer que estamos ante un texto del mismo tipo que los aquí consideramos comprobamos que el novelista no hace sino entrar en el debate crítico sobre la pertinencia del Naturalismo de Zola la Pardo Bazán había abierto en La cuestión palpitante. A pesar de que el texto de Valera tiene un carácter un tanto más práctico en algunas de sus partes no da nunca el paso a hablar de cómo se hace una novela sino de lo esta debe ser o no: «La novela histórica no puede pasar de moda. Ni aun para los más preocupados de las cuestiones sociales, religiosas y políticas del día. Todo se repite, todo tiene sus antecedentes en otras épocas, y quien las estudia tal vez da mayor luz a las cuestiones que más recientes parecen. Lo que impide que se escriban muchas novelas históricas, es que tal vez el naturalismo requiere que escribamos lo que vemos, y no las cosas pasadas. En éstas la imaginación debe trabajar mucho, y ya sabemos que el autor naturalista, o debe carecer de imaginación, o debe emplearla poco. La novela histórica exige, además, mucha preparación y mil estudios previos, sobre todo hoy que se hila muy delgado en lo tocante a la indumentaria y a otros conocimientos arqueológicos que han de prestar color exacto y tono conveniente a los pormenores» (Valera, 1934: 184).
} 
Sería muy razonable preguntarnos por qué estos textos surgen a partir de la segunda mitad del siglo XIX y su frecuencia se acentúa en las últimas décadas de este siglo y continúa de una manera más o menos constante con picos de intensidad hasta nuestros días.

Los principales factores que propiciaron su surgimiento en los albores del siglo XX fueron: La influencia de la crítica literaria, factores de índole socioeconómica, el surgimiento de nuevos géneros, y otros factores entre los que destaca la existencia de nuevas plataformas editoriales, especialmente las revistas periódicas especializadas en asuntos literarios.

Respecto de la influencia de la crítica literaria y las nuevas corrientes literarias hay que tener en cuenta que, tal y como señala Viñas Piquer ${ }^{5}$, el ideal de artista como creador no sustituye a la idea clásica del arte como imitación de formas y modelos hasta el siglo XIX, con el movimiento romántico. Fue precisamente este vuelco el que hizo posible pensar en la escritura libre de las normas del Decoro y este cambio de perspectiva abrió a su vez la necesidad de contar con nuevos materiales para la escritura, alejados de las viejas poéticas que constituían, precisamente, un cifrado de dichas normas.

Como señala Viñas Piquer, es posible que los aires revolucionarios de finales del siglo XVIII y el cambio de mentalidad que supone la formación del Estado Moderno contribuyeran al cambio en las ideas estéticas:

No puede negarse que las ideas revolucionarias contribuyeron a crear un cierto ambiente democrático. Se sentía que el hombre había sido liberado por fin, que ya no había hombres especiales por su poder reyes, príncipes - , que todos eran iguales. Trasladada esta idea al ámbito de la poesía, afecta directamente

En los artículos de Clarín sobre la materia tampoco encontramos discusiones sobre el proceso de la escritura sino cuestiones algo más prácticas, que se acercan a los temas que los nuevos textos tratarán, tampoco los abordan de lleno. Así en «La prensa y los cuentos», sobre la proliferación del cuento en la prensa española de la época: «Sería de alabar que los lectores y lectoras del folletín apelmazado, judicial y muchas veces justiciable, escrito en un francés traidor a su patria y a Castilla, se fuesen pasando del novelón al cuento; mejorarían en general de gusto estético y perderían mucho menos tiempo. El mal está en que muchos entienden que de la novela al cuento va lo mismo que del artículo a la noticia: no todos se creen Lorenzanas; pero ¿quién no sabe escribir una noticia? La relación no es la misma. El cuento no es más ni menos arte que la novela: no es más difícil como se ha dicho, pero tampoco menos; es otra cosa: es más difícil para el que no es cuentista. En general, sabe hacer cuentos el que es novelista, de cierto género, no el que no es artista» (Clarín, 1896).

El prólogo a la novela La Quimera, de Pardo Bazán sea quizá el único ejemplo de finales de siglo XIX en el que podemos encontrar un intento, aunque brevísimo, de dar cuenta del proceso de escritura, la autora hace en el mismo un repaso de algunas de los componentes de su obra, así describe cómo llegó a desarrollar su personaje principal a partir de la idea de la sátira social: «Ignoro lo que el desgraciado joven hubiese hecho; conozco, en cambio, lo que le agitaba y enloquecía, cómo se dejaba arrastrar palpitante en las garras de la Quimera; y la batalla entre su aspiración y las fatalidades de la necesidad me pareció tanto más dramática, cuanto que, para un artista en quien la Quimera no tuviese fijos sus glaucos ojos, la situación de halagado retratista de damas hubiese sido gratísima y provechosa. El rapín bohemio, soplándose los dedos en su solitaria buhardilla, no me importa tanto como este otro bohemio rápidamente puesto de moda y celebrado, invitado a las casas de más tono, envuelto en sedas y encajes, asfixiado de perfumes, pero agonizando de nostalgia, despreciándose y acusándose de traición al ideal, y resignándose a la suerte ya la caricia de los poderosos, sólo porque esperaba que le proporcionasen manera de encaminarse a la cima ruda, inaccesible, donde ese ideal se oculta» (Pardo Bazán, 1905).

5 «El ideal de la perfección artística basado en un perfecto equilibrio entre el deleite y la utilidad dominó el panorama de la crítica literaria desde Horacio hasta el siglo XVIII, así que puede decirse que se trata de la principal actitud estética del mundo occidental. Pero a finales del XVIII y principios del siglo XIX el foco de atención se desplaza al poeta, y lo que pasa a interesar realmente es la constitución mental del escritor, sus facultades para la composición artística, su creatividad. Antes su invención y su imaginación estaban limitadas por el principio de la mímesis: había un modelo — la naturalezadel que no debía apartarse, y unos autores - los clásicos - a los que tenía que imitar. Pero cuando el centro de atención se desplaza hacia el poeta, progresivamente se va exaltando la libertad creadora, la imaginación y la espontaneidad emocional del creador, lo que, en conjunto, puede denominarse el genio natural. [...] Así el poema ya no es imitación, sino expresión de sentimientos: una especie de catarsis personal, de desahogo» (Viñas Piquer, 2007: 263). 
al principio neoclásico del decoro, según el cual la poesía de estilo elevado tiene que estar reservada para personajes y temas también elevados (Viñas Piquer, 2007: 278).

Estos cambios inspiraron a los críticos y autores románticos, como Wordswoth, quienes empiezan a romper esas normas en su propia poesía.

Sin embargo, el romanticismo, aunque supone una revolución desde el punto de vista ideológico no deja de presentar también ciertas dificultades para la concepción de la literatura como oficio, porque al irse a los extremos del Neoclasicismo y poner todo el peso de la balanza en el autor, cierra la puerta a cualquier consideración de tipo práctico sobre el oficio. Su máxima sería la de que la obra sale de la cabeza y corazón del poeta de manera espontánea, luego no habría tampoco la posibilidad de hablar de una metodología en la escritura, no habría más metodología que «dejar hablar al corazón».

De hecho, el surgimiento de esa metodología no se da hasta que se han superado también las posiciones románticas.

Dentro del propio romanticismo hubo, no obstante, algunos esbozos de lo que luego serán las nuevas posturas acerca de la composición. Tal es el caso de Coleridge, que defendía que el poema debe, en parte, construirse hasta formar un todo orgánico donde todas las partes sean armónicas.

Esta postura se va acercando a la de Edgar Allan Poe. Para acometer el empeño de escribir un texto sobre la escritura de ficción Poe rechaza, tiene que rechazar, y lo hace además de manera explícita, los principios fundamentales de la estética romántica. A pesar de que sus propias obras hayan sido y sigan siendo consideradas paradigma del romanticismo. Este rechazo, no obstante, le llevará a una especie de callejón sin salida, como luego veremos.

Hay además otro factor importante que contribuye al surgimiento y publicación de estos nuevos tratados sobre la escritura: el hecho de que durante el siglo XIX la novela y la narrativa en general se conviertan en el «plato fuerte» de la escena literaria. La irrupción en el panorama de la novela tendrá dos consecuencias, la primera sería la necesidad de tratados sobre este género preponderante, la segunda, que se hace mucho más fácil hablar de la narrativa como fruto de un proceso que sobre la poesía (género predominante hasta aquella fecha), bien por considerarse que la poesía es el resultado de seguir un conjunto estricto de normas textuales, o bien por considerarse que la poesía depende única y exclusivamente de la inspiración del autor.

Así, la mayoría de los textos que proliferan a finales del siglo XIX y principios del XX son textos sobre narración escritos por narradores. A pesar de que Poe, en su Filosofía de la composición, que es, como hemos comentado, el primero de los textos que se propone hablar sobre el proceso de escritura, hable de escritura de poesía. A partir de finales del XIX aunque se hable de «ficción», normalmente se quiere decir narración, aunque no estrictamente en todos los casos. Hemos encontrado excepciones a esta tendencia especialmente en los textos de las vanguardias y los años sesenta y setenta del s. XX, que bien tratan de todos los géneros indistintamente - casi siempre porque no distinguen entre los géneros - o bien se refieren específicamente al género poético.

Podría afirmarse que hay otros factores que posiblemente que contribuyeron de manera decisiva a la aparición de los nuevos textos sobre la escritura de ficción. 
La mayor parte de estos textos no aparecieron en volúmenes aislados sino como fragmentos, en distintos formatos. No será hasta entrado el siglo XX cuando este tipo de literatura será considerada con entidad suficiente como para constituir ella sola materia de libro e incluso así seguirá siendo común que los textos de estudio sean parte de recopilatorios de artículos, de correspondencias, de misceláneas, etc.

Todo hace pensar que la existencia de ciertas «plataformas» distintas de las del libro tradicional fue decisiva para que estos escritos proliferaran y acabaran considerándose merecedores de tiradas independientes.

La primera de estas «plataformas» fue la prensa escrita, ya afianzada a finales del siglo XIX, y los nuevos medios que se convierten en espacio de escritores, especialmente en EE.UU, pero también en Europa. No en vano, muchos de los textos que comentamos fueron publicados originalmente como artículos en revistas que se dedicaban fundamentalmente a la publicación de literatura o aspectos relacionados con ella: es el caso de los artículos de Baudelaire, de Stevenson, Clarín; que sólo posteriormente, algunos incluso en época muy reciente, fueron considerados apropiados para hacer con ellos una publicación independiente. Aquí hay que destacar la importancia que tuvieron medios como Scribner's Magazine para el mundo anglosajón, que propició la publicación de textos sobre el arte de la escritura desde su fundación en 1887, hasta su cierre en 1939, o de L 'Sprit Public en Francia.

Este tipo de revistas siguen siendo de vital importancia para la aparición de textos sobre el arte de la escritura también en el siglo XX, al menos hasta sus últimas décadas. Es imposible no mencionar aquí el impresionante acicate que para la materia supuso y sigue suponiendo hasta la fecha la sección «The Art of Fiction» de The Paris Review ${ }^{6}$, donde los más afamados escritores, desde la década de los cincuenta del siglo XX hasta hoy mismo, explican su aproximación al arte de la ficción. Actualmente y de publicación periódica seguimos contando, por ejemplo, con el material — ingente — que se publica en otros medios, preferentemente en lengua inglesa, como The Guardian ${ }^{7}$, que cuenta con un asombroso archivo dedicado al oficio y artes de la escritura.

Otra de las plataformas que posibilita el surgimiento de este tipo de literatura a finales del siglo XIX es la correspondencia entre escritores. Esta vía de reflexión, más o menos privada, fue la elegida por algunos de los que dedicaron su empeño a la materia. Algunos de estos textos fueron enseguida considerados de interés para el público y se editaron en el mismo siglo XIX. Es el caso de las cartas de Flaubert. Otros, como la correspondencia de Chéjov, antes mencionada, tardaron más tiempo en ver la luz.

¿Por qué se usó la literatura epistolar para este tipo de escritos? Ha de entenderse que esto variará según el caso. Por ejemplo en el de Flaubert lo más plausible es que fuera el suyo un afán de diálogo privado sobre cuestiones que le interesaban. También es bastante probable que aunque en algún momento pensara en hacer un ensayo con sus pensamientos al respecto, no llegara a acometerlo por

\footnotetext{
${ }^{6}$ La serie de entrevistas que constituye The Art of Fiction de The Paris Review puede ser consultada en línea desde los años cincuenta hasta hoy en: http://www.theparisreview.org/interviews/1950s\#list (última consulta, 31-12-2017).

7 The Guardian tiene también una ingente cantidad de materiales que pueden ser consultados en línea en https://www.theguardian.com/books/creative-writing (última consulta, 31-12-2017).
} 
falta de tiempo. Sin embargo, en otros casos, como en el de Chéjov, los motivos del uso de la correspondencia privada, tal y como explica Jesús García Gabaldón, fueron otros bien distintos:

En realidad, la literatura epistolar tuvo una importancia capital entre la intelligentsia rusa del siglo XIX y primeras décadas del XX. En una sociedad que carecía de vida política, opinión pública y libertad de prensa, en la que las obras literarias estaban sometidas a la censura, los géneros ensayísticos de la correspondencia privada y del diario son fundamentales para reconstruir la vida cultural y literaria (García Gabaldón, 2005: 11)

Sea como fuere, puede considerarse que las últimas décadas del siglo XIX supusieron para los tratados sobre la escritura un periodo fructífero y de grandes innovaciones, que sentaron las bases para la posterior literatura sobre la materia.

Todos estos factores, como venimos comentando, tendrán también su influencia en los textos sobre la escritura de ficción a lo largo del siglo Xx. Es notable, por ejemplo, el efecto que una escuela de pensamiento crítico como el estructuralismo ruso acabará teniendo en la práctica y reflexiones sobre la propia escritura. Y otro tanto puede decirse de la influencia de las ideas críticas y filosóficas de la vanguardia europea: surrealismo, dadaísmo, etc.

A pesar de que los textos iniciales sobre la materia surgen en el siglo XIX, lo cierto es que tal y como venimos comentando, la disciplina sufre repentinos renacimientos a lo largo del siglo XX en función del resurgimiento de nuevos contextos. Estos contextos pueden tener que ver con el surgimiento de nuevas corrientes de crítica literaria, como arriba comentábamos, con tesituras sociopolíticas - hay, por ejemplo, una rama completa de textos sobre la ficción que surge al abrigo de los grandes conflictos políticos de siglo Xx en Europa y Latinoamérica- u otros factores.

Así por ejemplo encontramos como en la Latinoamérica de los años sesenta a los años ochenta surgen textos relacionados con la eclosión de la práctica del taller literario en esta latitud, así lo explican los editores del texto del taller de escritura creativa de Bioy Casares:

Los talleres literarios se difunden en la Argentina a comienzos de la década de los 70, acaso porque la enseñanza universitaria de la literatura está principalmente dirigida a la formación de docentes, críticos e investigadores, descuidando el aspecto propiamente creativo del acto de escribir. Un taller literario está integrado por un grupo de cinco a diez personas cada uno, orientadas por un coordinador, que se ejercitan en la práctica de la escritura (corrección, estructura y estilo) y que reciben información teórica sólo en función de la lectura de sus textos (Della Paolera y Cross, 2007: 9).

Lo cierto es que el surgimiento de una nueva disciplina es un proceso complejo, pues lo que se anhelaba a finales del siglo XIX era una nueva perspectiva de aproximación a la realidad literaria, que no fuese desde el análisis, siempre a posteriori, sino desde el durante, en el proceso. Veremos cómo aún bien entrado el siglo Xx habrá autores que reclamen que no se han escrito suficientes textos sobre la materia, tal es el caso, por ejemplo, de otra de las autoras que se dedica a tal empeño, Edith Wharton. Así se expresaba, por ejemplo, aún en 1924 en una serie de artículos que publicó en la revista Scribner: «Estudiar la práctica de la ficción es enfrentarse a la más novedosa, la más fluida y la menos formulada de las artes» (Wharton, 2011: 22). 
Lo cierto es que estos primeros textos que intentan dar el salto entre la pura crítica literaria a la didáctica de la escritura de ficción o creativa o la descripción del proceso, adolecen de una conexión fatal con el formato textual de la crítica y no será hasta el siglo XX cuando aparecerán textos mucho más centrados en la enseñanza de los procedimientos de la ficción, como veremos.

En estos primeros textos, sin embargo, observamos una evolución que hará posible el surgimiento de esa nueva y ansiada perspectiva. Esa evolución comienza, como antes mencionábamos con el primero de los textos clásicos, La filosofía de la composición de Edgar Allan Poe, en el que el autor intenta desgranar la composición de su poema «El cuervo».

Poe defiende que su obra está escrita desde la práctica de la creación literaria. Aun cuando esta supuesta pretensión de la obra no fuera del todo honesta - convenimos con Viñas Piquer cuando dice que Poe, cuando detalla el proceso pretende no sólo mostrar dicho proceso, sino sobre todo «demostrar la falsedad de quienes dicen — según Poe — por una cuestión de pura vanidad - escribir al dictado de una misteriosa inspiración» (Viñas Piquer, 2007: 318). Esto es, escribir contra la poética romántica.

Como comentábamos arriba, si bien por un lado el romanticismo facilita el primer paso para que se pueda escribir sobre la escritura, por otro, lo imposibilita, al poner toda la importancia de la escritura en el genio del autor. Parece que Poe se hace plenamente consciente de este dilema y así trata de superar las ideas románticas para hacer una exposición «científica» del trabajo del escritor.

Sin embargo, la empresa que Poe se propone tiene sus escollos, tal y como señala Viñas Piquer, y como también había hecho Julio Cortázar en el magnífico prólogo a la edición castellana que él mismo tradujo ${ }^{8}$, cuesta cierto trabajo creer que Poe esté siendo del todo sincero cuando nos cuenta cómo ha sido concebido y elaborado su poema, haciendo sólo hincapié en la forma de la composición, y en ningún momento en los sentimientos que dieron origen a la obra u otras consideraciones.

De este modo, la Filosofía de la composición estaría a medio camino entre crítica y el escrito sobre la escritura. Tendrían que pasar todavía muchos algunos años para que los escritores empezaran a dar textos en los que se contase la cocina de la escritura sin supeditarla, o al menos sin supeditarla tanto, a intenciones teóricas. Será necesario, como veremos, acercarse a modos de escribir sobre la escritura que no sean los tradicionales de la crítica.

Veamos algunos ejemplos que justifican estas afirmaciones.

Poe empieza su tratado aludiendo a cómo ha de componerse lo que Aristóteles habría llamado «fábula» y nosotros llamaríamos «fábula» o trama y, sin salirse demasiado del postulado aristotélico, denuncia como falsario el método que supuestamente, tal como le transmite Dickens en una carta,

\footnotetext{
${ }^{8}$ «No hay duda de que en este poema hay mucho de excesivamente fabricado, tendiente a lograr un profundo efecto general por medio de la sabia gradación de efectos parciales, de preparación psicológica, de encantamiento musical. En este sentido, el relato que nos hace Poe de cómo lo escribió parece corroborarlo por los resultados. Se sabe, sin embargo, que la verdad es otra: El cuervo no nació de un plan infaliblemente preconcebido, sino de una serie de estados sucesivos (y obsesivos, pues Poe vivió varios años hostigado por el tema —nacido de la lectura de Barnaby Rudge, de Dickens-, probándolo en distintos planos, acercándose de a poco a la versión final), estados que se desalojaban o perfeccionaban mutuamente hasta alcanzar ese texto [...]. Es lícito sospechar, a la luz de un análisis global de impulsos y propósitos, que la relojería de $E l$ cuervo nace de la pasión más que de la razón, y que, como en todo poeta, la inteligencia es aquí auxiliar de lo otro, de eso que "se agita en las profundidades", como lo sintió Rimbaud» (Cortázar, 1987: 30).
} 
había sido empleado por William Godwin hacia 1794 en la composición de la novela Things as They are or the Adventures of Caleb Williams.

El supuesto método no había sido otro que el de empezar la novela por sus capítulos centrales, sin idea de cómo había sido el principio de las peripecias del personaje, escribir la parte final, para luego ir construyendo el principio.

Poe duda de la veracidad del método:

Me es imposible creer que tal método haya sido empleado por Godwin y, por otra parte, lo que él mismo ha confesado, no está absolutamente conforme con lo afirmado por Dickens; pero el autor de Caleb Williams era demasiado buen artista para no dejar de ver el beneficio que podría obtenerse de tal procedimiento. Sin duda alguna no hay verdad más evidente que para que un plan merezca el nombre de tal, debe haber sido cuidadosamente elaborado para preparar el desenlace, antes de que la pluma se pose sobre el papel. Únicamente teniendo continuamente ante el espíritu el desenlace, podemos dar a un plan su indispensable fisonomía de lógica y de casualidad, haciendo que todos los incidentes, y en particular el tono general, tiendan hacia el desarrollo de la intención (Poe, 2006: 203).

Así que la primera anotación de Poe es una anotación formal, es decir, va a hablar de la composición de la estructura de la obra y no de otras cosas, como veremos. Y a ese respecto Poe dice más o menos lo que el maestro Aristóteles había dicho ya en su día:

Las fábulas, o antiguas o nuevas, el mismo las pone en verso debe antes proponérselas en general, y después conformemente, aplicar los episodios y entrever las particularidades. Quiero decir que la fábula de la Ifigenia, por ejemplo, se puede considerar en general de esta forma: Estando cierta doncella a punto de ser sacrificada, y desaparecida invisiblemente de entre las manos de los sacrificantes, y trasplantada a otra región, donde por ley los extranjeros eran sacrificados a cierta diosa, obtuvo ese sacerdocio. El porqué vino allá, eso no es del asunto considerado en general, ni tampoco con qué fin vino (Aristóteles, 1999: 35-36).

Como anunciábamos, parece que Poe cae en la paradoja de volver a la poética clásica por querer huir de la estética romántica. Nada extraño si se tiene en cuenta que no existían muchos textos ni propuestas acerca de la descripción de proceso de construcción de ficciones.

Cuando finalmente Poe nos desvela las intenciones de su obra, que no son otras que las de desterrar «errores» en la composición de las historias, según dice. Parece que nos encontramos entonces ante un tratado normativo más que descriptivo, lo que entra en contradicción con su supuesta intención meramente descriptiva y evidencia la paradoja en la que el autor se estaba moviendo. Como el propio Poe explica: «He elegido "El cuervo", como más conocido. Mi deseo es demostrar que ningún punto de la composición puede ser atribuido a la casualidad o a la intuición, y que la obra ha marchado, paso a paso, hacia su solución con la precisión y la rigurosa lógica de un problema matemático» (Poe, 2006: 204).

Esta contradicción o extraña mezcla entre la pura descripción del proceso creativo y la evidente intención de describir ese proceso de manera que invalide otros y se constituya en norma, es constante en el tratado. En el que finalmente Poe acaba por defender sus presupuestos estéticos más que describir cómo escribió «El cuervo»: «Lo Bello es el único dominio legítimo de la poesía [...] Ahora bien, el objeto, Verdad o satisfacción del intelecto, y el objeto, Pasión, o excitación del corazón, son, aunque 
ellos también estén en cierta manera al alcance de la poesía, mucho más fáciles de obtener por medio de la prosa» (Poe, 2006: 203).

Lo que vamos encontrando, pues, más que un tratado acerca de la práctica de la escritura son resonancias de todo el racionalismo occidental, desde Platón hasta Kant y un afán evidente por desterrar otras teorías estéticas, como antes aludíamos. Esta teoría estética será expuesta con más longitud y profundidad en otro de los ensayos de Poe: The Poetic Principle, que fue por primera vez publicado después de su muerte, en 1850. En este artículo Poe insiste en su idea de que el fin de todo arte es la elevación del alma que se produce al contemplar la belleza — «El valor del poema se halla en relación con estímulo sublime que produce. [...] Sólo en la contemplación de Lo Bello podemos alcanzar esa grata elevación del alma que reconocemos como Sentimiento Poético» (Poe, 1987: 819) - y de que el arte debe ser independiente de otras consideraciones, especialmente las consideraciones didácticas que habían sido defendidas por muchos de sus contemporáneos.

Para Poe el método adecuado de composición, tal y como explica después, es el que parte del efecto que la obra quiere provocar; esto es, el escritor debe preguntarse: ¿Qué efecto quiero provocar? ¿Cómo ser original? Y dependiendo de la respuesta que se dé a estas dos preguntas aparecerá una secuencia lógica de pasos en la composición, tal y como él mismo explica que le sucedió con la composición de «El cuervo».

Para Poe, de estos dos «axiomas» más dos subaxiomas: búsqueda de cierta complejidad y que la obra contenga algún poder de sugestión, se obtendrán de manera «científica» todos los elementos de la obra: extensión, tono, personajes, trama, etc.

Para Poe la circunstancia particular que origina la composición de la obra, así como su intención, o la necesidad de componerlo son irrelevantes, como no podía ser de otro modo ya que estamos en el paradigma del platonismo occidental: la idea, la belleza están en un plano aparte y superior al del mundo sensible.

En una exposición que se torna cada vez más inverosímil el autor explica cómo cada elemento de la obra debe subordinarse a la emoción o efecto que se quiere causar. Así, el autor plantea que el cálculo del grado de excitación exacto que quería conseguir con su obra dará el número exacto de versos: «Teniendo presentes en mi espíritu estas consideraciones, así como el grado de excitación que no coloqué por encima del gusto popular ni por debajo del gusto crítico, primeramente concebí la idea de la extensión conveniente de mi proyectado poema, unos cien versos, y en realidad no tiene más que ciento ocho» (Poe, 2006: 205).

El segundo aspecto de la composición que Poe dice haber considerado es el tono; aludiendo a este, y teniendo en cuenta que lo quiere es provocar el mayor elevamiento del alma, cuenta que se le hizo evidente que el tono debía ser el de la tristeza. Se hizo evidente dice, y aquí ya no recurre a la matemática sino a lo que llama «experiencia humana», que si lo pretendía era la elevación del alma el tono debía ser triste.

Es inevitable constatar cómo Poe en su afán por desterrar la idea de la intuición romántica vuelve a retomar uno de los postulados principales de Aristóteles, el de la finalidad de la obra de arte, en 
particular de la tragedia — que es la única parte de la Poética que conservamos-. Para Aristóteles cada género tenía por objeto último provocar un efecto o emoción en el lector-espectador:

Hablaremos ahora de la tragedia, resumiendo la definición de su esencia, según lo que resulta de las cosas dichas. Es, pues, la tragedia representación de una acción memorable y perfecta, de magnitud competente, recitando cada una de sus partes por sí separadamente, y que no por modo de narración, sino moviendo a compasión y terror, dispone la moderación de estas pasiones (Aristóteles, 1999: 25).

A lo largo de la Poética Aristóteles explicará cómo cada uno de los componentes de la tragedia, personajes, fábula, características morales o el mismo estilo, se han de componer de una manera determinada supeditada a la finalidad, que es la de causar esa emoción de compasión y terror. Así por ejemplo, cuando explica la elección de personajes dirá:

[...] es manifiesto que no se han de introducir ni personas muy virtuosas que caigan de buena en mala fortuna (pues esto no causa espanto ni lástima, sino antes, indignación) ni tampoco malvadas, que de mala fortuna pasen a buena (pues ésta entre todas las cosas es ajenísima de la tragedia, y nada tiene de lo que se pide, porque ni es humano, ni lastimoso, ni terrible); ni tampoco sujeto muy perverso, que dichoso pare en desdichado; porque tal constitución, dado que ocasione algún natural sentimiento, no producirá compasión ni miedo; porque la compasión se tiene del que padece no mereciéndolo; el miedo es de ver el infortunio en un semejante nuestro. Así que tal paradero no parece ni lastimoso ni temible. Resta pues el medio entre los dichos, y éste será el que no es aventajado en virtud y justicia, ni derrocado de la fortuna por malicia y maldad suya, sino por yerro disculpable, habiendo antes vivido en la gloria y la prosperidad, cuales fueron Edipo, Tiestes y otros ilustres varones de antigua y esclarecida prosapia (Aristóteles, 1999: 31).

También respecto del tono encontramos similitudes con Aristóteles, pues para el Estagirita, el tono - elevado, medio, bajo - estaba dictado por el tipo de héroe que se quisiera imitar y a su vez por el tipo de efecto que esto pudiera provocar: terror, compasión, burla o risa.

En su afán por huir de la propuesta romántica Poe cae no sólo en la vuelta a la poética clásica sino que también su obra adolece de otra clara influencia filosófica: Poe quiere ser tan radical que prácticamente elimina el elemento subjetivo de la escritura, pretendiendo asimilar el proceso de composición poética con un proceso científico. Muy en consonancia con las corrientes del positivismo tan en boga en la cultura occidental del siglo XIX y especialmente en el mundo anglosajón en el que, desde los estudios de Occam, allá en los últimos tiempos del medievo, el empirismo ha sido la actitud común ante el conocimiento en general.

$\mathrm{Ni}$ una ni otra influencia teórica ayudan en exceso al autor para proporcionarnos un texto realmente centrado en el arte de la escritura de ficción como era su intención original. Sí contribuyeron, sin embargo, a que se pusiera de manifiesto lo dificultoso de la empresa y la necesidad de un cambio total de perspectiva que no se producirá hasta décadas después.

En el mismo año que Poe en Estados Unidos publica su Filosofía de la Composición, Baudelaire, publicaba en Francia unos apuntes sobre el oficio de escritor: Conseilles aux jeunes littérateurs. Éstos aparecieron originalmente en L'Esprit public y fueron recogidos el año siguiente, 1845, en Le Salon du 1845 (Baudelaire, 2010). 
En estos escritos, Baudelaire trata desde los denuedos del inicio de la carrera de escritor, hasta los sinsabores de la falta de éxito, las amistades literarias y sus beneficios y perjuicios o la pertinencia o no de vapulear a los contrarios.

Baudelaire defiende que antes de producir la obra debe tenerse la idea bien clara en la cabeza y haberla meditado y madurado. Aquí no dista mucho de la idea de Poe, y tampoco lo hace en su consideración del trabajo frente a la musa: «Una alimentación sustancial, pero regular es la única cosa necesaria para los escritores fecundos. Decididamente, la inspiración es hermana del trabajo diario. Estos dos contrarios no se excluyen más que todos los contrarios que constituyen la naturaleza» (Baudelaire, 2010).

Sin embargo, en las anotaciones de Baudelaire hay algo que será esencial para se pueda hablar del oficio de escribir en lo sucesivo: su tono, desenfadado, permite que el texto se cuelen «otras cosas»: desde la necesidad de alimento o dinero y cómo solventarlo, hasta la relación que se ha de establecer con las amantes. Es decir, consideraciones prácticas, que, hasta aquella fecha, eran consideradas impropias del texto sobre la ficción.

Este punto de vista, además, abre la puerta a consideraciones parecidas que irán apareciendo si no en el siglo XIX sí en el XX. De hecho, habrá una corriente entera de textos que tratan sobre los aspectos más puramente materiales, sociales, etc., que formarían también parte del proceso de escritura 9 .

En 1884 Henry James publica uno de los textos que se convertirá en clásico de los tratados sobre escritura: The Art of Fiction. El texto apareció por primera vez en la revista Longman's Magazine, en septiembre de 1884. Era la respuesta a otro texto de título homónimo de Sir Walter Besant, que había visto la luz en abril del mismo año.

Curiosamente Henry James, quien aboga por un tipo de novela moderna, elige la novela La isla del tesoro de Robert Louis Stevenson - que había visto la luz en 1883- como modelo de una «nueva novela». Y decimos curiosamente porque esa misma novela servirá a su autor una década más tarde

\footnotetext{
${ }^{9}$ Podríamos citar, por ejemplo, el clásico de Virginia Woolf, Una habitación propia, o el mucho más reciente de Patricia Higsmith, Suspense. El tema que pone sobre la mesa la obra de Woolf es fundamentalmente el de las condiciones materiales que permiten a un individuo escribir ficción: «La obra de imaginación es como una tela de araña: está atada a la realidad, leve, muy levemente quizá, pero está atada a ella por las cuatro puntas. A veces la atadura es apenas perceptible; las obras de Shakespeare, por ejemplo, parecen colgar, completas, por sí solas. Pero al estirar la tela por un lado, engancharla por una punta, rasgarla por en medio, uno se acuerda de que estas telas de araña no las hilan en el aire criaturas incorpóreas, sino que son obra de seres humanos que sufren y están ligadas a cosas groseramente materiales, como la salud, el dinero y las casas en que vivimos» (Woolf, 2008: 61).

Highsmith, por su parte en Suspense cuenta cómo se las puede arreglar el escritor principiante ganarse la vida y la importancia para la obra de esos ingresos: «Algunos escritores jóvenes se presionan demasiado y fuerzan la máquina. Cuando eres joven, esto puede funcionar, hasta cierto punto. Pero siempre llega el momento en el que el subconsciente se rebela, las palabras se niegan a salir, las ideas se niegan a nacer, el cerebro está exigiendo unas vacaciones, puedas permitírtelas o no. Por eso es buena idea para un escritor contar con un trabajo alternativo que le dé algo de dinero, hasta que tenga suficientes libros en su haber como para que le proporcionen un goteo constante de ingresos» (Highsmith, 2010: 23).

En este libro la autora no sólo se centra en las condiciones más materiales de la escritura sino en muchas otras como en el proceso de creación de la obra en la estela de los estudios de Stevenson que se comentarán abajo.
} 
para describir el que quizá sea el texto sobre el arte de la escritura más contemporáneo de todos los que se dan al final del siglo XIX, como abajo explicaremos.

Una de las primeras cosas que llaman la atención en el texto de James es que éste tiene un lector objeto que se hace explícito, unas veces nombrado como el «romancier», otras como «el joven aspirante al arte de la ficción», todo hace indicar que ha surgido un nuevo lector, el aspirante a escritor, interesado en aprender el arte de la ficción que no es el lector ideal de los escritos de Poe, que parecían aún moverse en el cerrado terreno de la crítica. El hecho de que haya ya establecido un público al que se dirigen este tipo de textos no puede ser más relevante para el desarrollo de la disciplina. A partir de James la existencia de este lector se dará por hecha de manera explícita o implícita en la mayoría de los textos sobre el arte de la ficción.

El texto de James, que lleva precisamente por título El arte de la ficción no puede ser, sin embargo, más decepcionante si lo que se busca es un estudio sobre cómo se componen las ficciones. James parte de la idea de que es imposible describir el método para escribir una novela, aquí refuta a Besant, que defendía que la novela tiene unas leyes que pueden ser expuestas sin mayor dificultad. Entre otras normas Besant enumera: que se debe partir de personajes reales, que no se deben mezclar las clases sociales, o que la novela inglesa debe tener un fin moral. Besant está claramente haciendo un discurso anacrónico en su propia época, prácticamente neoclásico - las normas del Decoro- que parece haber desoído no sólo las corrientes de la última época del siglo XIX, que ya anunciaban como la propia obra de James - el modernismo, sino incluso la teoría romántica. Es fácil de entender por qué, en este punto, James se opone a la idea de Besant de que se pueda «explicar cuáles son las normas de la novela» y que opte por discutir que se pueda hablar si quiera de cómo se construye la novela:

Es aquí precisamente donde, paso a paso trabaja como su hermano del pincel, del que podemos siempre decir que ha pintado su cuadro de la mejor manera que sabe. Su manera es su secreto, no siempre tan celosamente guardado. Aunque pueda revelarlo como algo común, si lo hiciera, tendría dificultades en enseñárselo a otros. Digo esto teniendo en cuenta que he insistido en lo que tienen en común los métodos del artista que pinta un cuadro y del artista que escribe una novela. El pintor es capaz de enseñar los rudimentos de su praxis, y es posible, a partir del estudio de una buena obra (supuesta la actitud), tanto de aprender a pintar como de aprender a escribir. Mas sigue siendo cierto, sin menoscabo para el rapprochement que el artista literario se vería mucho más obligado que el otro a decir a su alumno: “¡Bien, has de hacerlo como puedas!" (James, 1992: 47-49).

Las únicas orientaciones de James son las de que la novela debe ser interesante y la de que la novela es: «una impresión personal y directa de la vida. En principio eso constituye su valor, que es mayor o menor según la intensidad de esa impresión» (James 1992: 47).

Quizá el quid de la cuestión en 1884, sea que se pretendía hacer del arte de la ficción un catálogo de normas y recomendaciones; tal y como se había heredado de la poética clásica y del propio clasicismo y esa propuesta no servía para el estudio del arte de la ficción, tal y como empieza a entenderse después del Romanticismo. 
James va más allá e insiste no sólo en la imposibilidad de decirle al escritor novel en qué debe fijarse o qué estilo debe cultivar sino que además propone la consideración de la novela como organismo:

La novela es algo vivo, un todo completo y continuo como cualquier otro organismo, y en la medida en que esté viva se comprobará, según creo, que en cada una de sus partes hay algo de cada una de las demás. El crítico que ante la textura cerrada de una obra acabada pretenda trazar una geografía de los elementos, me temo que marcará algunas fronteras tan artificiales como las conocidas de la historia (James, 1992: 55-57).

Si bien es cierto que James no da materiales que puedan ser digamos «utilizables» por el aspirante a escritor, y que además parece cerrar el camino a cualquier texto que trate en serio de plantear una didáctica del oficio de escritor, consideramos, sin embargo que está allanado el camino al surgimiento de los textos modernos sobre escritura creativa al desterrar los últimos vestigios de la crítica neoclásica y demostrar que el arte de la ficción no puede ser abordado como un tratado de geometría: es decir, no hay axiomas, no hay premisas y corolarios-: «Señores, olvídense del método científico en estos asuntos», parece estar James soplándonos al oído—. Tampoco hay «temas artísticos»:

Todas son partículas de la vida multitudinaria de que trata la novela, y seguramente ningún dogma que pretenda que sea lícito tratar una e ilícito tratar la otra podrá sostenerse en pie ni un solo momento. Un determinado cuadro debe carecer de ella. Mr. Besant, según mi opinión, no aporta luz a la cuestión al indicar que un argumento, bajo pena de no serlo, debe consistir en "aventuras". ¿Por qué aventuras más que verdes escenarios? Menciona una categoría de cosas imposibles y entre ellas coloca la "ficción sin aventura". ¿Por qué sin aventura más que sin matrimonio, celibato, parto, cólera, hidropatía o jansenismo? Me parece que esto hace retroceder la novela al pequeño y desventurado rôle de algo artificial, ingeniosos; rebaja su cualidad grande y libre de inmensa y exquisita correspondencia con la vida (James, 1992: 69).

Podríamos decir que James hace posible un cambio de «paradigma»: que por un lado pone el acento en la conciencia del escritor ${ }^{10}$, en su mirada sobre el mundo, y por otro descarta que se pueda hacer un estudio sistemático o normativo o científico del arte de la escritura. Pero si no se puede acometer el estudio del arte de la escritura como un sistema, tal y como Poe o Besant quisieran hacer, la pregunta que queda en el aire es: ¿Cómo se puede acometer esta empresa? La respuesta, no tardará

\footnotetext{
${ }^{10}$ De hecho, se puede considerar que la obra de James es la primera de una serie de obras que proliferarán a partir de principios del siglo XX y que podríamos denominar «Estudios sobre la conciencia del escritor». Entre estas obras podrían citarse los estudios sobre escritura de Kafka, Pavese, Lispector, Duras, Orwell, Cortázar, Sabato o Monterroso.

Por ejemplo, en estudios de Kafka, hay un replanteamiento de qué es la escritura a partir del cuestionamiento de la propia conciencia del artista y de su construcción, que Kafka dibuja como una tarea titánica siempre acosada por las estrecheces económicas y las obligaciones laborales y las imposiciones familiares: «Ayer escribí de forma casi inconsciente "El maestro de pueblo", pero tenía miedo de escribir hasta después de las dos menos cuarto de la madrugada. El temor era fundado; apenas dormí, sólo tuve tres pequeños sueños, y en la oficina me encontré en un estado fatal. Ayer los reproches del padre por la fábrica: "Buena plancha has hecho". Luego fui a casa, escribí tranquilo durante tres horas, consciente de que mi culpa es indudable, aunque no tan grande como me la pinta mi padre. Hoy sábado no he acudido a cenar, en parte por temor a mi padre, en parte para aprovechar la noche por entero para el trabajo, aunque sólo llegué a escribir una página no demasiado buena» (Kafka, 2003: 102).

O, por ver otra muestra de este tipo de estudios, podríamos remitirnos a los estudios de Duras sobre la necesidad de la construcción de un espacio de soledad, físico y mental para que la conciencia del escritor pueda fructificar: «Alrededor de la persona que escribe libros siempre debe haber una separación de los demás. Es una soledad. Es la soledad del autor, la del escribir. Para empezar, uno se pregunta qué es ese silencio que lo rodea. Y prácticamente a cada paso que se da en una casa y a todas horas del día, bajo todas las luces, ya sean del exterior o de las lámparas encendidas durante el día. Esta soledad real del cuerpo se convierte en la, inviolable, del escribir» (Duras, 1994: 16).
} 
en llegar y vendrá no sólo de un lugar, sino de varios, los textos sobre la escritura de Stevenson, Flaubert y Chéjov.

En el año 1905, once años después de la muerte de Robert Louis Stevenson, apareció en Londres un volumen que llevaba por título Essays in the art of writing (publicados en España como El arte de escribir). Los textos recogidos en el volumen habían ido viendo la luz entre 1881 y 1894 en diversas revistas británicas.

En ellos, Stevenson trata de múltiples asuntos relacionados con el arte de la escritura, alternando las anotaciones sobre la escritura de prosa y verso. A pesar de que algunos de los artículos, especialmente los dedicados a la poesía, aún adolecen de estar más cercanos a la crítica que a la exposición del proceso de escritura, lo cierto es que podemos decir que con los textos acerca de la escritura narrativa, especialmente de La isla del tesoro Stevenson da un giro que podríamos llamar copernicano por lo que supone de cambio de perspectiva respecto de la materia.

Lo primero que reconoce el autor, y no es desdeñable, es que los resortes totales de la escritura de ficción no pueden ser desvelados por completo por lo que tienen de azaroso e inconsciente y así: «El aficionado, en consecuencia, recibirá siempre a regañadientes los detalles del método, que puede ser expuesto pero nunca explicado por completo» (Stevenson, 2006:17). Estamos aquí ya lejos de la disputa de Poe contra la teoría poética romántica y mucho más cerca de los que serán los planteamientos a partir de siglo XX, con la sombra del inconsciente asomando en la escena. Nótese también como Stevenson habla del aficionado (a la escritura) pues es ya un hecho aceptado como arriba comentábamos que hay un público, el de los aficionados o aspirantes a escritores que anhela este tipo de estudios.

¿Cómo describe Stevenson el método de la escritura para ese escritor novel? Lo que hace, primeramente, es hablar de tres asuntos fundamentales: la necesaria formación del escritor y los fracasos que preceden la composición de cualquier obra de valor, la dificultad de ganarse la vida con la escritura y las imposiciones que de esto derivan, en su caso: el imperativo de escribir novela, pues de otro género no se podía vivir.

También comentará Stevenson asuntos como el necesario soporte familiar y de seres cercanos, o la longitud del texto, debida a imposiciones externas, no de la obra.

Como vemos, el autor está trayendo a primer término problemas externos al texto retomando la estela de los textos de Baudelaire y James. Estas consideraciones volverán a aparecer en los grandes escritos sobre la materia del siglo XX, como ya comentábamos arriba al hilo de los textos de Baudelaire.

Una vez que ha expuesto las circunstancias que podríamos llamar «externas» a la obra, aunque ya esta categoría empieza a hacer aguas, el autor se emplea en la descripción del proceso productivo de la obra en sí misma. Así describirá los orígenes de la obra, a partir de un mapa real que dibujó con su hijastro y que le devolvió a las historias de piratas que su padre le contaba en la infancia, la inspiración para personajes en personas de su entorno, la influencia de Irving y Dafoe (semiconsciente), la ayuda de su propio padre y de su familia, a la que leía la obra a medida que se iba escribiendo. 
Stevenson hace un especial hincapié en los materiales de la ficción, un aspecto este totalmente novedoso. Stevenson insiste en la importancia del mapa real que dibujó para la Isla del Tesoro y de ahí hace extensible la recomendación al escritor:

No es, quizá, infrecuente que un mapa figure de forma tan principal en una historia, pero siempre es importante. Un autor debe conocer sus territorios, ya sean reales o imaginarios, como su propia mano; las distancias, los puntos cardinales, el lugar por donde se pone el sol, las fases de la luna, todo esto no debería constituir motivo de reflexión» (Stevenson, 2006: 78).

Además de mapa Stevenson recomienda otros «materiales»:

Yo cometí algunos errores con la luna en Príncipe Otto y, tan pronto como me fueron señalados, adopté la precaución, que recomiendo a otros, de no escribir en adelante sin disponer de un almanaque. Con un almanaque, un mapa de la región, y un plano de las casas, ya sea realmente diseñado en papel, ya memorizado de inmediato, uno puede ser capaz de evitar algunas de las mayores meteduras de pata (Stevenson, 2006: 78).

Así que mapas, planos, almanaques, son, en opinión de Stevenson elementos útiles en la tarea del narrador. No sólo para evitar posibles errores sino también como fuente de inspiración, tal y como explica en el último párrafo de su texto:

Pero incluso con lugares imaginarios hará bien al principio en proveerse de un mapa; al estudiarlo, se le harán evidentes relaciones en las que antes no había pensado, descubrirá obvios, aunque insospechados, senderos y atajos para sus mensajeros, e incluso cuando un mapa no constituya la trama en sí, como ocurría en La isla del tesoro, encontrará en él una mina de sugerencias (Stevenson, 2006: 78-79).

Además de estas consideraciones puramente compositivas Stevenson resaltará otros elementos como: la relación con el mundo editorial o el público, como elementos también consustanciales al proceso creativo.

De modo que en la reflexión sobre su propio trabajo como escritor Stevenson llega a la conclusión de los materiales de la ficción, por así decir, constituyen o pueden constituir no sólo guía orientativa sino también fuente de inspiración, pues inspiración y técnica, planificación y desarrollo están tan imbricados que no tiene sentido, para el creador, claro está, desligarlos. Estamos ante el primer intento verdaderamente logrado de descripción del proceso de escritura por parte de un creador con todas las dificultades y paradojas que esto implica y que a Stevenson, como arriba veíamos, no se le escapaban.

Existe, un terreno intermedio, nos viene a decir Stevenson - como si estuviera respondiendo a la pregunta que James dejara abierta-, en el que el creador puede hablar de su obra, de su metodología y de su proceso de composición y orientar a otros escritores sin hacer un tratado de crítica literaria.

Para llevar a cabo ese cometido Stevenson recurre a lo que mejor sabe hacer: narrar. En esta narración hay un protagonista, el propio autor, un objetivo, la consecución de la obra, unos impedimentos para que el héroe logre su empeño, la falta de conocimientos, la desorientación, la premura, las estrecheces económicas, los editores, etc., y unas herramientas y materiales que, a modo de espada metafórica, ayudarán al escritor a superar sus dificultades y dar caza a su dragón particular. 
Por supuesto en esta epopeya también habrá personajes secundarios: familia, amigos, otros escritores y escritos que ayudarán o pondrán en mayores aprietos al héroe.

Los textos que Stevenson presenta no son, claro está, puramente narrativos, hay en ellos argumento y reflexión, pero el lector tiene la impresión de que se está enfrentando a otra cosa, a un nuevo enfoque a la hora de poner sobre el tapete el oficio de la escritura.

No todos los tratados del siglo Xx copiarán el modelo de Stevenson, habrá trabajos mucho más argumentativos, más recopilatorios, etc. Pero muchos harán uso del recurso narrativo y de otros recursos de la ficción para enfrentarse a tratar el arte de la escritura; y posiblemente éstos sean los más $\operatorname{ricos}^{11}$.

Otros dos grandes textos servirán como guía y abrirán nuevas perspectivas para el territorio de los estudios sobre la escritura de ficción son las correspondencias de Flaubert y Chéjov. Flaubert nos ofrecerá una descripción de su trabajo como escritor en los aspectos más detallados y Chéjov, a su vez, arrojará luz sobre una parte del proceso normalmente oculta: el de la revisión y la reescritura.

Flaubert no deja nada en el tintero en su intensísima correspondencia, desde el deseo de escribir y la educación de la mirada y la relevancia de los mismos para la composición de los textos - algo que no había sido tratado prácticamente hasta él—, hasta la inspiración, la documentación, la preescritura, la escritura propiamente dicha, la reescritura y correcciones, el estilo como guía y dificultad, la crítica o el dinero.

Extraemos algunos fragmentos que ejemplifican hasta qué punto Flaubert dejó testimonio de todos estos factores y de su importancia capital en la propia escritura.

Atendiendo, por ejemplo, al deseo y la mirada, en carta a A Ernest Chevalier, 23 de febrero de 1842:

Hay que acostumbrarse a no ver en las personas que nos rodean otra cosa que libros. El hombre sensato las estudia, las compara, y de todo esto hace una síntesis que le es útil. El mundo para el verdadero artista sólo es un clavicordio; es a él a quien corresponde obtener sonidos que fascinen o que hielen de espanto. La

\footnotetext{
${ }^{11}$ Nos referimos estudios en los que el autor describe, normalmente en forma de narración, el proceso de escritura de alguna de sus obras. Podríamos mencionar, por ejemplo: Iluminación y temblor nocturno, la autobiografía de Carson McCullers, que incluye exquisitas narraciones acerca de los procesos de escritura de sus obras, escrita a finales de los años sesenta y publicada en 1999. Historia secreta de una novela de Vargas Llosa de 1971 en la que describe cómo escribió La casa verde. El soldado español de Härtling que describe el proceso de escritura de uno de sus relatos. El arte de la novela, de Kundera de 1986 y que incluye fragmentos narrativos sobre la inspiración del novelista.

Veamos dos ejemplos de estas obras para que se comprenda el tipo de aproximación al proceso de escritura que proponen: De Vargas Llosa, por ejemplo, vemos la defensa de la síntesis de recuerdos y de trabajos dispares para conformar el mundo unitario de su novela: «Al final sobrevino una especie de caos: el desierto y la selva [...] Era demasiado fatigoso seguir luchando por apartados, así que decidí no hacerlo más: fundir esos dos mundos, escribir una sola novela que aprovechara toda esa masa de recuerdos. Me costó tres años y abundantes tribulaciones ordenar semejante desorden» (Vargas Llosa, 2001: 55-56).

Veamos también, como ilustración, un fragmento McCullers en el que relata cómo llegó a entender las características del principal personaje de su novela El corazón es un cazador solitario: «Entonces, mientras caminaba de un extremo al otro de la alfombra de mi sala de estar, saltándome los cuadrados del dibujo, y agotada por un problema que yo misma había creado, se me ocurrió de golpe la solución. El protagonista, el silencioso, siempre se había llamado Harry Minowitz; pero, mientras yo pensaba y caminaba, me di cuenta de que era sordomudo, y por eso los demás siempre le hablaban a él, y él, claro, nunca les contestaba. Fue una verdadera iluminación, que dio luz a cada uno de los personajes y enfocó todo el libro» (McCullers, 2001:31-32).
} 
buena y la mala sociedad deben ser estudiadas. La verdad se encuentra en todo. Comprendamos cada cosa y no censuremos ninguna (Flaubert: 1998: 221).

Veamos otro ejemplo, esta vez de documentación para Madame Bovary:

Esta mañana he estado en unos comicios agrícolas, de donde he vuelto muerto de cansancio y de aburrimiento. Necesitaba ver una de esas necias ceremonias rústicas para mi Bovary, en la segunda parte. Sin embargo, ahí se encuentra lo que denominan Progreso y en él converge la sociedad moderna. Me encuentro enfermo físicamente (Flaubert, 1998: 159).

Cuando Flaubert describe el mismo proceso de escritura también resulta revelador y su perspectiva es, desde luego, la del creador. Famosos son los pasajes en los que describe cómo sentía las afecciones de sus personajes para poder llegar a componer las escenas, así lo describe en una carta a A Louise Colet, 23 de diciembre de 1853:

A las seis, en el momento en que escribía las palabras "ataque de nervios" estaba tan excitado, gritaba tan fuerte y sentía de manera tan profunda lo que mi mujercita experimentaba, que he temido sufrir yo mismo un ataque. Me he levantado de la mesa y he abierto la ventana para ver si podía calmarme. La cabeza me daba vueltas. Ahora me duelen mucho las rodillas. [...] bien o mal, escribir es algo delicioso, la posibilidad de no ser uno mismo, de circular por toda la creación. Hoy, por ejemplo, he sido hombre y mujer, amante y querida simultáneamente, me he paseado a caballo por un bosque, en una tarde de otoño, bajo las hojas amarillas, y era los caballos, las hojas, el viento, las palabras que se decían y el sol rojo que hacía entrecerrar sus párpados anegados de amor (Flaubert, 1998: 159).

El cambio cualitativo de los escritos de Flaubert sobre la escritura respecto otras obras anteriores es una suerte de síntesis: entre el trabajo de la imaginación que propone Stevenson y el trabajo de corrección, más técnico, más cercano a la postura de Poe.

Esta panorámica del trabajo del escritor, sería además, omniabarcadora, no olvidemos que a partir de esta correspondencia se pueden deducir otros aspectos del trabajo del escritor como puedan ser la relación con la publicación, con la crítica, e incluso con el dinero. En este sentido Flaubert también recoge los que podríamos llamar aspectos externos de la escritura que Baudelaire había sido pionero en tratar.

También como en Stevenson asoma aquí un tratamiento novedoso del escrito sobre la escritura, de nuevo tenemos una narración en que la que el protagonista es el autor, aunque quizá en el caso de Flaubert esto tenga más que ver con el estilo epistolar que con una voluntad clara.

Las cartas de Flaubert, especialmente aquellas destinadas a los aspectos sobre la composición y el trabajo literario, influyen en la literatura sobre el oficio de la escritura más bien en el siglo XX. Y lo mismo puede aplicarse al caso de Chéjov, que veremos a continuación ${ }^{12}$. Chéjov, poco dado a disquisiciones generales sobre qué es el arte, qué es el estilo, etc., se dedica en sus cartas a dar consejos prácticos, precisos y adecuados a cada una de las obras que sus amigos le van enviando. Esto conforma una especie de corpus sobre los temas técnicos de la escritura que casi parece un tratado contemporáneo

\footnotetext{
${ }^{12}$ Ecos de la correspondencia de Flaubert pueden encontrarse por ejemplo en las Conversaciones en el taller literario, donde Bioy Casares abre directamente su intervención mencionando la epopeya que Flaubert cuenta en sus cartas y lo mucho que esto divertía Henry James. En Cartas a un joven novelista, por poner otro ejemplo, de Mario Vargas Llosa, publicada en 1997, el autor peruano discute sobre el método de escritura de Flaubert y cita buena parte del contenido de las cartas del autor francés.
} 
sobre el oficio, quizá porque, en parte, los tratados actuales siguen la estela de Chéjov, uno de los escritores más citados en talleres y ensayos sobre el arte de escribir.

Y no en vano, puesto que Chéjov, que escribe directamente a familiares y conocidos que se acercaban a él con sus obras incipientes, se aplica en los detalles prácticos de corrección de la escritura que pueden resultar realmente reveladores. Sirvan estos ejemplos para explicar a qué nos referimos:

Por ejemplo en carta a María K. Kiseliova de 3 de diciembre de 1889:

Uno de estos días recibirá la invitación para enviar, en enero, un cuento de caza, por supuesto no muy grande, lleno de poesía y de belleza. Más de una vez usted observó cacerías con galgos, gente de Pskov, etc., y no le será difícil crear alguna cosa adecuada. Puede, por ejemplo, escribir una crónica titulada Iván Gavrílov o El alce herido. En este último cuento, si no lo ha olvidado, unos cazadores hieren un alce que les mira de una forma tan humana que ninguno se atreve a matarle. Ese argumento no está mal, pero es peligroso por ser difícil evitar sentimentalismos. Es necesario escribirlo de manera protocolaria, sin palabras de lástima, comenzando así: "En tal día, en el bosque de Daraganovski, unos cazadores hirieron un joven alce..." (Chéjov, 2005: 38).

O un segundo ejemplo, de esta carta a Lidia A. Avílova de 15 de febrero de 1895:

¿Para qué necesita su heroína palpar la capa superior de la nieve con un bastón rígido?, ¿y por qué rígido? Eso es para las levitas o los muebles. Y en la capa superior de la nieve también hay una expresión inútil, como la capa superior de la harina o la capa superior de la arena. Acto seguido se encuentran frases como: "Nikifor se separó del pilar de la puerta", o esta otra: "él gritó y se alejó de la pared". Escriba una novela. Escríbala un año entero, luego durante medio año redúzcala, y después, imprímala. Usted se esfuerza poco, una escritora no debe escribir, sino bordar en el papel para que el trabajo sea lento y minucioso... (Chéjov, 2005: 49).

La mayor aportación de Chéjov, sin embargo, para el desarrollo de la disciplina de los textos sobre escritura de ficción no son sin embargo sus consejos concretos, sino el hecho de que Chéjov parte del supuesto, y así lo repite en las cartas de una u otra forma, de que la escritura es un oficio que puede ser aprendido y enseñado.

Así, con la confluencia de estas tres últimas obras que hemos comentado, Stevenson, Flaubert, Chéjov estaría ya allanado el camino para el desarrollo de los textos sobre la escritura de ficción del siglo XX, superadas tanto las dificultades teóricas: el abandono de la estética neoclásica y de la romántica, como las prácticas: la construcción de estos nuevos textos se hará primordialmente desde la reflexión sobre el oficio por parte de los propios creadores y usará habitualmente de formatos textuales híbridos entre la ficción y la argumentación.

A partir del siglo XX, como ya hemos ido comentado, se abrirán varias perspectivas para los textos sobre escritura creativa. Tendremos así textos que abunden sobre la formación de la conciencia del escritor, textos sobre las condiciones de posibilidad de la escritura desde el punto de vista social y material y otra gran rama de textos que será la que dé cuenta de procesos concretos de escritura.

Habrá, aparte de estas ramas, otra nueva que es la de los textos que tratarán sobre la conexión con la parte inconsciente como método de llegar a la escritura creativa. Pero para que estos textos vean 
la luz será aún necesario que se produzca una revolución en la filosofía y la teoría literaria que no eclosionará hasta la década de los años veinte: la de las vanguardias europeas ${ }^{13}$.

\section{Obras citadas}

ARISTÓTELES (1999): Poética. México, Porrúa.

BAUDELAIRE, Charles (2010): Consejos a jóvenes escritores. Edición digital, Musa a las 9.

Bioy CASARES, Adolfo (1988): Conversaciones en el taller literario. Madrid, Ediciones y Talleres de Escritura creativa Fuentetaja.

BRADBURY, Raymond (1995): El zen y el arte de escribir. Barcelona, Ediciones Minotauro.

BurRoughs, William (1981): «William Burroughs», en George PliMPTON, ed., Hablan los escritores.

Barcelona, Kairós, pp. 169-171.

CHÉJOv, Anton (2005): Consejos a un escritor. Cartas sobre el cuento, el teatro y la literatura. Madrid, Ediciones y Talleres de Escritura Creativa Fuentetaja.

ClaRín (1896): «La prensa y los cuentos», en Crítica Popular; en http://www.cervantesvirtual.com/ obra-visor-din/critica-popular--0/html/ff68712a-82b1-11df-acc7-002185ce6064_3.html\#I_0_ (última consulta, 31-12-2017).

CORTÁzar, Julio (1987): «Prólogo», en PoE, Edgar Allan, Ensayos y críticas. Madrid, Alianza, pp. 13-61.

Della PaOlera, Félix - Cross, Esther (2007): «Prólogo», en Bioy CASARES, Adolfo, Sobre la escritura. Conversaciones en el taller literario. Madrid, Ediciones y talleres de escritura creativa Fuentetaja, pp. 9-11.

DoLEZEL, Lubomír (1997): Historia breve de la poética. Madrid, Síntesis.

DURAS, Marguerite (1994): Escribir. Barcelona, Tusquets.

García Gabaldón, Jesús (2005): «Prólogo», en ChÉJOv, Anton, Consejos a un joven escritor. Madrid, Ediciones y Talleres de Escritura creativa Fuentetaja, pp. 9-13.

HighSMith, Patricia (2010): Suspense. Barcelona, Mosaico.

\footnotetext{
${ }^{13}$ Será esta también una estela fructífera para los textos sobre la ficción, que dará lugar a no pocos estudios. Todas estas nuevas ramas de los textos sobre escritura creativa serán expuestas en posteriores estudios, pero para que el lector entienda de qué tipo de textos hablamos pondremos aquí algunos ejemplos finales: los trabajos de Miller, los de Bradbury o los de Burroughs, entre otros.

Veamos alguna de las técnicas que propone Burroughs: «Recientemente he realizado muchos experimentos con cuadernos de apuntes. Leo en el periódico algo que me recuerda o tiene alguna relación con algo que he escrito. Recorto la fotografía o el artículo y lo pego en un cuaderno de apuntes junto a las palabras de mi libro. O si voy caminando y de repente veo una escena de algún libro mío, la fotografío y la pongo en una libreta de apuntes. He descubierto que cuando preparo una página, casi invariablemente sueño esa noche con algo relacionado con esa yuxtaposición de palabra e imagen. En otras palabras, he estado interesado en ver precisamente cómo palabra e imagen se relacionan formando asociaciones muy, muy complicadas. Hago muchos ejercicios en lo que yo llamo tiempo de viaje, tomando coordenadas, como lo que fotografié en el tren, lo que estaba pensando en ese momento, lo que estaba leyendo, y lo que escribí; todo ello para ver hasta qué punto puedo proyectarme hacia un punto del pasado» (Burroughs, 1981: 170).

O, por poner un último ejemplo, vemos las recomendaciones de Bradbury: «Busque un personaje como usted que quiera algo o no quiera algo con toda el alma. Dele instrucciones de carrera. Suelte el disparo. Luego sígalo tan rápido como pueda. Llevado por su gran amor o su odio, el personaje lo precipitará hasta el final de la historia. La garra y el entusiasmo de esa necesidad - y tanto en el amor como en el odio hay garra-, encenderán el paisaje y elevarán diez grados la temperatura de su máquina de escribir» (Bradbury, 1995:15-16).
} 
Highsmith, Patricia (2010): Suspense. Barcelona, Mosaico.

HoRACIO (1777): Arte poética o Epístola a los Pisones; en http://www.cervantesvirtual.com/portales/ jorge isaacs/obra-visor-din/arte-poetica-de-horacio-o-epistola-a-los-pisones-traducida-en-verso -castellano--0/html/ (última consulta, 31-12-2017).

JAKOBSON, Roman (1988): Lingüística y poética. Madrid, Cátedra.

JAMES, Henry (1992): El arte de la ficción. León, Universidad de León.

KAFKA, Franz (2003): Escritos sobre el arte de escribir. Madrid, Ediciones y Talleres de Escritura creativa Fuentetaja.

KUnDERA, Milan (2012): El arte de la Novela. Barcelona, Tusquets.

LUZÁN, Ignacio de (1737): La poética o reglas de la poesía en general y de sus principales especies; en http://www.cervantesvirtual.com/obra-visor-din/la-poetica-o-reglas-de-la-poesia-en-generaly-de-sus-principales-especies--0/html/ (última consulta, 31-12-2017).

MCCULLERS, Carson (2001): Iluminación y temblor nocturno. Barcelona, Seix Barral.

PARDO BAZÁN, Emilia (1891): La cuestión palpitante, en http://www.cervantesvirtual.com/obra-visordin/la-cuestion-palpitante--0/html/ (última consulta, 31-12-2017).

PoE, Edgar Allan (1987): Ensayos y críticas. Madrid, Alianza.

- (2006): «La filosofía de la composición» en Ensayos. Buenos Aires, Claridad, pp. 203-213.

RODARI, Gianni (1983). Gramática de la fantasía. Barcelona, Argos Vergara.

STEVEnSON, Robert Louis (2006): El arte de escribir. Santa Cruz de Tenerife, Artemisa.

Todorov, Tzvetan - Ducrot, Oswald (1975): Diccionario Enciclopédico de las ciencias del lenguaje. Argentina, Siglo XXI.

VALERA, Juan (1934): Apuntes sobre el nuevo arte de escribir novelas, en Obras completas, Tomo XXVI. Madrid, Imprenta Alemana.

VARGAS LlOSA, Mario (2001): Historia secreta de una novela. Barcelona, Tusquets.

- (1997): Cartas a un joven novelista. Barcelona, Planeta.

VIÑAs PIQUER, David (2007): Historia de la Crítica Literaria. Barcelona, Ariel.

WARTHON, Edith (2011): Escribir Ficción. Madrid, Páginas de Espuma.

WoOLF, Virginia (2008): Una habitación propia. Barcelona, Seix Barral. 